\title{
Congenital hernia of umbilical cord with patent vitellointestinal duct along with evisceration of gut-a rare presentation and unusual management
}

\author{
Chandrodaya Kumar, Md Mokarram Ali ${ }^{*}$ i] and Yogender Singh Kadian
}

\begin{abstract}
Background: Congenital hernia of umbilical cord is a rare congenital anomaly. Due to its presentation as herniation of small bowel or other viscera into the umbilical cord, it is often misdiagnosed as omphalocele minor.

Case presentation: We are reporting a rare case of congenital hernia of umbilical cord which presented with rupture of hernia sac and evisceration of small bowel loops with reverse ileal intussusception via a patent vitellointestinal duct. It was managed by first repositioning the gut with stoma at umbilical site as a temporizing measure followed by definitive surgery in the form of resection of patent vitellointestinal duct and end to end ileal anastomosis.

Conclusion: Congenital hernia of umbilical cord with patent vitellointestinal duct is a rare abdominal wall defect which can present beyond neonatal period with evisceration of gut. A high index of suspicion should be kept by the first attending clinician to avoid a delay in management.
\end{abstract}

Keywords: Congenital, Omphalocele, Umbilical, Vitellointestinal

\section{Background}

Congenital hernia of the umbilical cord (CHUC) is a rare congenital anomaly and is characterized by herniation of small bowel and/or other viscera into the umbilical cord. It occurs due to failed closure of umbilical ring. A thin strip of normal skin always enwraps the umbilical ring and proximal part of the cord. Although recognized as a distinct entity since 1920s, CHUC is often misdiagnosed as a minor omphalocele, resulting in its underreporting $[1,2]$. The CHUC with contents as patent vitellointestinal duct (PVID) and its remnants or atresia and even perforation of herniated gut has been reported $[3,4]$. We are reporting one such rare case of this anomaly which presented with rupture of hernia sac and evisceration of

\footnotetext{
*Correspondence: mohdmokarramali1990@gmail.com Department of Pediatric Surgery, Pandit Bhagwat Dayal Sharma Post Graduate Institute of Medical Sciences, Rohtak, India
}

small gut with reverse ileal intussusception via PVID. It was successfully managed in two steps: first by repositing the gut into abdomen at the time of arrival and then subsequently by abdominal exploration with resection of the vitellointestinal duct. In this report, the idea and need of staging the management of the index case in two steps will also be discussed.

\section{Case presentation}

A 46-day-old male child weighing $3.4 \mathrm{~kg}$ was admitted in pediatric emergency with evisceration of small intestine through the umbilicus. The baby was full term, born by normal vaginal delivery at a peripheral center. At the time of delivery, the umbilical cord clamp was applied by the pediatrician which was not flush with skin (as told by parents while admission) probably due to umbilical cord hernia. The baby had a persistent discharge from umbilical stump and the consistency of it was watery, 
sometime greenish in color for which parents took treatment from local practitioner. On the day of admission, there was prolapse of gut via umbilicus because of which, the baby was referred to our institute. On closer examination at the time of arrival, it was observed that the gut was coming out via a normal umbilical ring and there was intussusception of the ileal loop through a patent vitellointestinal duct making a provisional diagnosis of ruptured sac of the hernia of the cord with PVID (Fig. 1). The child was sick and investigation revealed hemoglobin $8.5 \mathrm{~g} / \mathrm{dl}$ and blood urea $52 \mathrm{~m} / \mathrm{dl}$ and serum sodium 135 $\mathrm{meq} / \mathrm{L}$ and potassium more than $6 \mathrm{meq} / \mathrm{L}$. Because of poor general condition and dyselectrolytemia, the patient was managed in the emergency itself. Under sedation, the intussusception was reduced and small gut was reposited back into abdominal cavity after widening the umbilical ring The ileal segment with PVID was fixed to the umbilicus as stoma as a temporary measure (Fig. 2). Then patient was resuscitated with intravenous fluids, antibiotics, and infusion of packed cell volume. The general condition of the child improved and small gut started functioning via the enterotomy. Patient was then taken to operation theater after $36 \mathrm{~h}$ for exploration under general anesthesia. The ileal segment along with PVID was resected and end to end ileal anastomosis was performed. Patient recovered well in postoperative period. Subsequently, he was discharged home in a week in good general condition. Histopathological examination of the

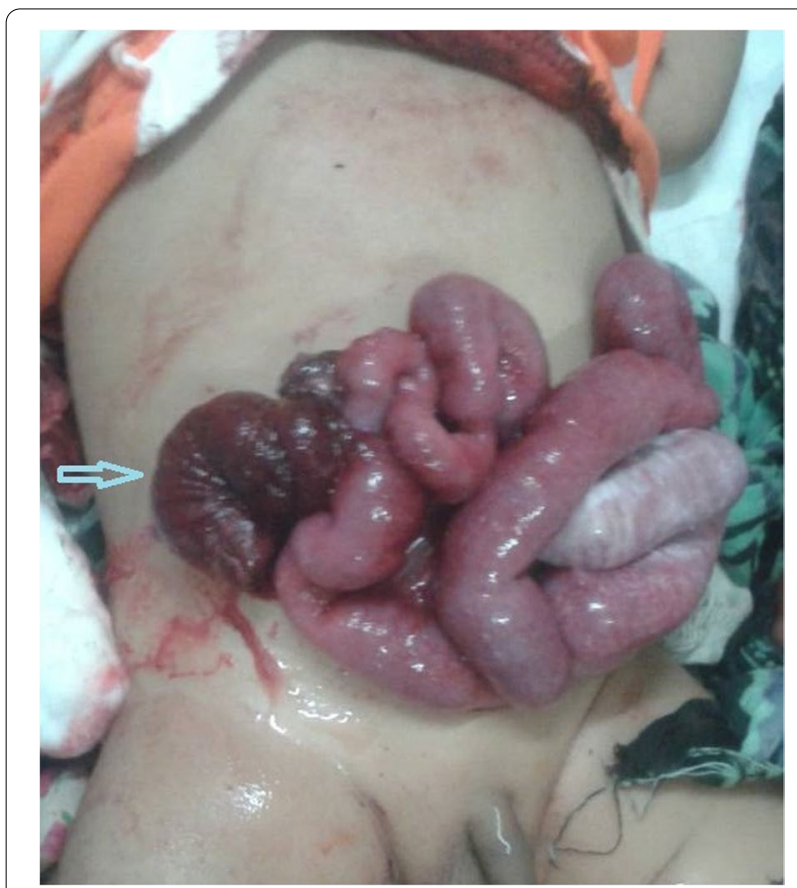

Fig. 1 Clinical photograph showing the evisceration of the small gut with reverse intussusception (arrow)

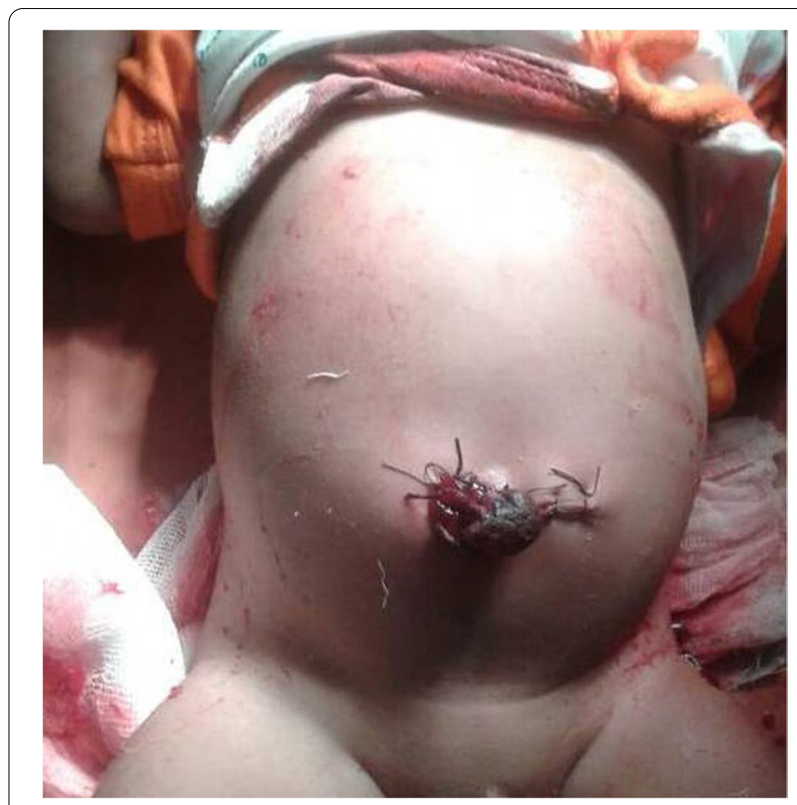

Fig. 2 Clinical photograph after reduction of gut loops with stoma on the abdominal wall

resected portion of the vitellointestinal duct revealed ileal mucosa.

\section{Discussion}

The reported incidence of congenital hernia of umbilical cord (CHUC) is low [ 1 in 5000] as compared to postnatal umbilical hernia, partly because most of these are misdiagnosed as omphalocele minors [5]. Embryologically, during early fetal life, a greater portion of the intestine lies in the proximal part of the umbilical cord which is called as extracelomic cavity. Normally, the intestines withdraw into the abdominal cavity at about 10-12 weeks gestation, the umbilical ring closes and the extracelomic cavity is thereby obliterated. In rare cases, the umbilical ring does not close and in these situations variable portions of the intestines remain in the extracelomic cavity, which persists as congenital hernia into the umbilical cord. So, the CHUC is a separate entity which is distinct from other anterior abdominal wall anomalies such as gastroschisis and omphalocele [6]. The characteristic features of CHUC are as follows: an intact umbilical ring, absent abdominal wall deficiency, a cuff of skin from one half to one inch wide, which extends from the abdominal wall onto the neck of the sac which comprises of an outer layer of amnion and inner peritoneum and its contents varying from loops of the intestine to any movable intraperitoneal organ and even liver and gall bladder as contents have been reported $[7,8]$.

The associated anomalies in hernia of the cord are PVID; congenital short gut; and intestinal atresia, ileal, 
and colonic atresias probably as a consequence of intrauterine vascular accidents such as volvulus, intussusception [9]. In rare instances, even fetal demise has been reported owing to rupture of umbilical cord that led to in utero bowel evisceration and rupture of umbilical vessels [10]. The present case presented with evisceration of gut via patent vitellointestinal duct and with reverse intussusception even in post neonatal period. This case has been described as a case of CHUC because of history of swelling over umbilicus and a small umbilical defect; however, it is difficult to rule out the omphalocele minor. By reporting this case, the authors aim to highlight the aspect of management of such a presentation. There are reports where the umbilical cord hernia has been overlooked at the time of birth and even clamped resulting in ischemia and injury of intestines [11]. Even meconium discharge from patent vitellointestinal duct in case of CHUC has also been reported as in the index case [7]. Gasparella et al. reported a case of an intestinal laceration due to clamping of an unrecognized herniation of umbilical cord in a newborn [12]. Although in the index case, cord clamping had not resulted in injury of intestine but callous umbilical cord clamping have been observed in literature [13].

\section{Conclusion}

The congenital hernia of umbilical cord with patent vitellointestinal duct is a rare abdominal wall defect which can present beyond neonatal period with evisceration of gut. A high index of suspicion should be kept by the first attending clinician to avoid a delay in management as happened in the index case. Every pediatrician should be made aware of such types of umbilical lesions and an early referral for a pediatric surgical consultation is the key to avoid such a delayed presentation with its complications. However, when faced with a case like the present one, an out of box solution may be required to avoid the further complication.

\section{Abbreviations}

CHUC: Congenital hernia of umbilical cord; meq/L: Milliequivalent per liter: PVID: Patent vitello intestinal duct.

\section{Acknowledgements}

None

\section{Authors' contributions}

MMA—collection of patient record and intra-operative pictures and writing the manuscript; YSK — proof reading of manuscript; CK and DG_editing of manuscript texts and pictures. All authors have read and approved the manuscript.

\section{Funding}

None

Availability of data and materials

Not applicable

\section{Declarations}

Ethics approval and consent to participate

Not applicable

\section{Consent for publication}

Written informed consent was obtained from the parent as patient is minor.

\section{Competing interests}

The authors declare that they have no competing interests.

Received: 29 July 2021 Accepted: 5 December 2021

Published online: 07 March 2022

References

1. Burns CW, Ogryzlo MA. Congenital hernia into the umbilical cord; two cases, one associated with persistent cloaca. Can Med Assoc J. 1938;39:438-41.

2. Tow R. Diseases of the newborn. New York: Oxford Medical Publication; 1937. p. 224-6.

3. Mirza B, Mirza A, Hashim I, Saleem M. Hernia of umbilical cord: report of three unusual case. J Neonatal Surg. 2015;4:16-8.

4. Pal K. Congenital hernia of the umbilical cord associated with extracelomic colonic atresia and perforation of gut in a newborn. Afr J Paediatr Surg. 2014;11:74-6.

5. Raicevic M, Filipovic I, Sindjic-Antunovic S. Hernia of the umbilical cord associated with a patent omphalomesenteric duct. J Postgrad Med. 2017:63(1):58-9. https://doi.org/10.4103/0022-3859.198157 PMID: 28079045; PMCID: PMC5394823.

6. Gajdhar M, Kundal VK, Mathur P, Gajdhar M. Pitfalls in the umbilical pit: giant hernia of the umbilical cord. BMJ Case Rep. 2013:2013:bcr2013009381.

7. Jona JZ. Congenital hernia of the cord and associated patent omphalomesenteric duct: a frequent neonatal problem? Am J Perinatol. 1996:13:223-6.

8. Hasaniya NW, Premaratne S, Varnes PM, Shin D, Shim W. Hernia into the umbilical cord with incarceration of liver and gall bladder in a newborn. J Pediatr Surg Case Rep. 2013;1:432-3.

9. Mirza B, Saleem M. Hernia of umbilical cord with congenital short gut. J Neonat Surg. 2014;3:26.

10. Haas J, Achiron R, Barzilay E, Yinon Y, Bilik R, Gilboa Y. Umbilical cord hernias: prenatal diagnosis and natural history. J Ultrasound Med. 2011:30:1629-32.

11. Vassy LE, Boles ET Jr. latrogenic ileal atresia secondary to clamping of an occult omphalocele. J Pediatr Surg. 1975;10:797-800.

12. Gasparella M, Zanatta C, Ferro M, Marzaro M, Benetton C, et al. latrogenic intestinal laceration secondary to clamping of unrecognized umbilical cord hernia: a case report. J Women's Health Care. 2014;3:177.

13. Kierkegaard A, Bjerring OS, Rasmussen L. The umbilical cord of newborn babies should be clamped at least five centimetres from the abdominal wall. Ugeskr Laeger. 2011;173:2270-1.

\section{Publisher's Note}

Springer Nature remains neutral with regard to jurisdictional claims in published maps and institutional affiliations. 